Article

\title{
Association of Rs339939442 in the AHR Gene with Litter Size are Inconsistent among Chinese Indigenous Pigs and Western Commercial Pigs
}

\author{
Qian Zhang 1,2, Ruihua Huang 1,2 (D), Xiang Ma ${ }^{1,2}$, Nengjing Jiang ${ }^{1,2}$, Wuduo Zhou ${ }^{1,2}$, \\ Chen Gao ${ }^{1,2}$, Moran Zhao ${ }^{1,2}$, Peipei Niu ${ }^{2}$, Zongping Zhang ${ }^{2}$, Qiang Li ${ }^{3}$, Juan Zhou ${ }^{3}$ \\ and Pinghua $\mathrm{Li}^{1,2, *}$ \\ 1 Institute of Swine Science, Nanjing Agricultural University, Nanjing 210095, China; \\ zhangqian_1992@126.com (Q.Z.); rhhuang@njau.edu.cn (R.H.); xiang.ma@zafu.edu.cn (X.M.); \\ jiangnengjing@163.com (N.J.); zhouwuduo@njau.edu.cn (W.Z.); GC1594140795@126.com (C.G.); \\ zmr787635834@163.com (M.Z.) \\ 2 Huaian Academy, Nanjing Agricultural University, Huaian 223005, China; niupeipei2@126.com (P.N.); \\ zongpingzhang@126.com (Z.Z.) \\ 3 Huaiyin Pig Breeding Farm of Huaian City, Huaian 223322, China; 13912078083@139.com (Q.L.); \\ 15261762741@163.com (J.Z.) \\ * Correspondence: lipinghua718@njau.edu.cn
}

Received: 17 November 2019; Accepted: 12 December 2019; Published: 19 December 2019

Simple Summary: Litter size is one of the most important economic traits in pig production. However, it is slow to improve litter size by traditional breeding methods. It has been paid much 1attention to improving pig litter performance by using marker-assisted selection and genomic selection. Our research indicated that $r s 339939442$ in the aryl hydrocarbon receptor (AHR) gene could be a marker to improve litter size in European commercial lines and Chinese Suhuai pigs containing genomic fragments of British Yorkshire pigs, and the litter size could be improved by selecting the individuals with favorable genotype (TT) of $r$ s339939442 for pig breeding.

Abstract: Eastern and Southern Chinese pigs have been imported to Western countries to improve economic traits including fertility in Western pig breeds by intensive selecting Chinese advantage genes. It was reported that the selected Asian-derived non-synonymous mutations including rs339939442 (G > T) in the aryl hydrocarbon receptor $(A H R)$ gene could increase litter size in multiple European commercial lines. The objective of this study is to identify whether $r s 339939442$ in the $A H R$ gene is polymorphic and has an influence on the litter size in 10 pig populations including five Chinese indigenous breeds, one cultivated breed, one lean-type breed, two North American lean-type breeds, and one European lean-type breed. We found that $r s 339939442$ had polymorphism in all 10 populations, whereas rs339939442 was associated with litter size only in French Yorkshire (FRA-Y) and Chinese cultivated Suhuai (SH) pigs containing approximately 75\% British Yorkshire pigs ancestry. Our results indicated that $r s 339939442$ in the $A H R$ gene was a potential marker to improve litter size in European commercial lines and the pigs containing ancestries of European commercial lines, whereas this locus maybe not a causal mutation affecting the litter size but only in linkage disequilibrium with the causal mutation for litter size.

Keywords: AHR gene; rs339939442; chinese pigs; western pigs; litter size; association analysis 


\section{Introduction}

As one of the most important reproductive traits, litter size is a complex quantitative trait, which is affected by many factors such as genetics, nutrition, parity, nutrition, the year and season, thus the heritability of litter size is very low, which is only about 0.1 [1]. Increasing litter size by using marker-assisted selection and genomic selection can bring huge economic benefits. Therefore, there have been many studies on candidate genes and causal mutations for litter size [2,3].

Chinese indigenous pigs are divided into six types including Jianghai pigs of East China and Southern Chinese pigs [4]. Jianghai pigs including Erhualian (EHL), Meishan (MS) and Jiaxinghei (JXH) pigs are well known for their high fecundity [5]. However, the reproductive performance of Bamaxiang (BMX) and Wuzhishan (WZS) pigs representing the Southern Chinese pigs are not prominent, which the average litter size was 10.07 and 6.58 for multiparous sows, respectively [5].

As early as the end of the seventeenth century, the United Kingdom had imported Southern Chinese pigs to improve the performance of their indigenous pigs and then cultivated the famous Yorkshire pigs. Since 1979, Jianghai pigs of East China including the MS breed were introduced in France and other Western countries for their exceptional characteristics such as prolificacy and superior meat quality [6,7]. Some advantage genomic fragments in Chinese pig breeds have been strongly selected and left as selection signals among European pig breeds [8]. Through genome-wide resequencing analysis and 60K chip sequencing, the $r s 339939442(\mathrm{G}>\mathrm{T})$ of the aryl hydrocarbon receptor $(A H R)$ gene was considered to be a Chinese high-yield fragment introduced into the European pig genome, and rs339939442 in the AHR gene was considered to be a potential causal mutation affecting the litter size in European commercial lines [8]. The AHR gene is a ligand-activating transcription factor belonging to the PER-ARNT-SIM (PAS) family and it can mediate a variety of in vivo biological processes such as immune system balance, cell growth and proliferation, vascular tissue remodeling [9,10]. It has been found that the $A H R$ gene can affect reproductive traits in mice and pigs [11,12]. However, it is still unknown that whether the rs339939442 in the AHR gene is polymorphic in Eastern and Southern Chinese pigs and whether this single nucleotide polymorphism (SNP) is associated with the litter size of Chinese indigenous pigs, newly cultivated pigs, lean-type pigs and North American lean meat pigs.

In this research, a total of 10 pig populations including the Eastern Chinese Jianghai pig breeds (EHL, MS and JXH), the Southern Chinese pig breeds (BMX and WZS), Chinese cultivated Suhuai (SH) pigs, which contains approximately 25\% Chinese Huai pigs and $75 \%$ British Yorkshire pigs ancestries [13], Chinese lean-type Taiwanese Landrace pigs (TPE-L), Western commercial pigs including Canadian Yorkshire (CAN-Y) pigs, American Yorkshire (USA-Y) pigs and French Yorkshire (FRA-Y) pigs were used to study whether the rs339939442 in the AHR gene is polymorphic and associated with the litter size in Chinese and Western pigs.

\section{Materials and Methods}

\subsection{Animals and Data Collection}

All experimental procedures and animals were carried out according to the Guidelines for the Care and Use of Laboratory Animals prepared by the Nanjing Agricultural University Animal Care and Use Committee (Certification No.: SYXK (Su) 2017-0007). The ethics committee of Nanjing Agricultural University approved this study. A total of 6943 animals from 10 diverse pig populations including five Chinese indigenous breeds representing two ecotypes, one Chinese cultivated breed, one Chinese lean-type breed, two North American lean meat pig breeds, and one European lean meat pig breed were investigated in this research (Table S1).

We investigated the Eastern Chinese Jianghai pigs and Southern Chinese pigs since they were both exported to Western countries and were representative of the high and low yield pigs in China, respectively. We collected phenotypic data and ear tissue samples of Chinese indigenous pigs from national or provincial conservation farms in China. EHL and MS pigs were collected from three conservation farms, respectively. Of them, Erhualian pigs were collected from Changzhou Jiaoxi 
Cooperatives of Erhualian pigs (JX-EHL), Changshu Animal Husbandry and Veterinary Station (CS-EHL) and Sutai Enterprise Co., Ltd. (ST-EHL), respectively; MS pigs were collected from Kunshan Meishan Pig Protection Co., Ltd. (KS-MS), Sutai Enterprise Co., Ltd. (ST-MS) and Taicang Pig Farm (TC-MS), respectively. The other pigs from each Chinese indigenous breed were sampled from one conservation farm. Of them, JXH pigs were collected from Qinglian, Zhejiang Food Co., Ltd.; BMX pigs were collected from Yangzhou Yiluxian Ecological Agriculture Technology Co., Ltd. and WZS pigs were collected from National Wuzhishan pig conservation farm in Lingshan Town, Haikou.

We collected phenotypic data and ear tissue samples of Chinese cultivated pigs, Chinese and Western lean-type breed from one commercial farm. Of them, $\mathrm{SH}$ pigs were collected from Huai'an Huaiyin Pig Breeding Farm; TPE-L pigs were collected from Guangdong Wangjiang Pig Co., Ltd.; CAN-Y pigs were collected form Fujian Yichun Agricultural Development Co., Ltd.; USA-Y pigs were collected from Jinggangshan Aoxinhuafu Breeding Co., Ltd. and FRA-Y pigs were collected from Henan Xinda Animal Husbandry Co., Ltd. (Table S1).

During the consecutive years (2008-2018), data of total number of born (TNB) and number of born alive (NBA) were collected from 2367 parities of 574 EHL sows (1478 parities of 343 JX-EHL sows, 550 parities of 156 CS-EHL sows and 339 parities of 75 ST-EHL sows), 1708 parities of 395 MS sows (1210 parities of 263 KS-MS sows, 283 parities of 79 TC-MS sows and 215 parities of 54 ST-MS sows), 2465 parities of $845 \mathrm{SH}$ sows, 10,264 parities of 3095 TPE-L sows, 3101 parities of 1252 CAN-Y sows, 704 parities of 359 FRA-Y sows and 1326 parities of 365 USA-Y pigs (Table S1). It is a pity that there is no detailed litter size record for JXH, BMX and WZS.

Ear tissue from the right ear of each sow was collected and stored in $75 \%$ alcohol for genomic DNA extraction. Since some sows were eliminated from the farm before sampling, we only collected ear tissues of 363 EHL sows including 177 JX-EHL sows, 116 CS-EHL sows and 70 ST-EHL sows; 273 MS sows including 153 KS-MS sows, 47 ST-MS sows and 73 TC-MS sows; 62 JXH sows; 32 BMX sows; 20 WZS sows; 314 SH sows; 351 TPE-L sows; 425 CAN-Y sows; 345 USA-Y sows and 359 FRA-Y sows for subsequent genomic DNA extracting and genotyping (Table S1).

\subsection{DNA Extraction and Single Nucleotide Polymorphisms Genotyping}

Genomic DNA was extracted from ear tissue using a standard phenol/chloroform method. The DNA concentration and integrity were detected to select high-quality genomic DNAs for subsequent genotyping. The primers (F: AGCAGCAGCAACAACTGTGT, R: GACACAGCTCCACCATAGCA) of the $r s 339939442$ were used to amplify a fragment of $427 \mathrm{bp}$ [8]. PCR was carried out with an initial denaturing step at $98^{\circ} \mathrm{C}$ for $2 \mathrm{~min}$ and then 35 cycles at $98^{\circ} \mathrm{C}$ for $10 \mathrm{~s}, 61^{\circ} \mathrm{C}$ for $10 \mathrm{~s}$ and $72{ }^{\circ} \mathrm{C}$ also for $10 \mathrm{~s}$, and a final extension at $72{ }^{\circ} \mathrm{C}$ for $2 \mathrm{~min}$. The PCR products are sent to the company (TsingKe, Nanjing, China) for Sanger sequencing. After the sequencing finished, DNAman software was used to verify the accuracy of the sequence, and then Chromas software was used to determine the SNP loci and for genotyped. According to the reference genome information, $T$ is the variant $(G>T)$.

\subsection{Statistical Analysis}

\subsubsection{Phenotypic and Gene Frequency Descriptive Statistics}

The descriptive statistics and difference analysis of NBA and TNB for seven pig populations (EHL, MS, SH, TPE-L, CAN-Y, FRA-Y and USA-Y pigs) were performed by SPSS 20.0 software (SPSS Inc., Chicago, IL., USA). The records of TNB and NBA of less than five were removed as previously reported [14]. Since there is no genetic exchange among different farms of the EHL or MS pig breed, the phenotypic data from different herds within a pig breed cannot be combined to calculate the estimated breeding values (EBV) value of TNB and NBA. Here we only use the phenotypic data of JX-EHL pig, which contains more than 150 individuals, to calculate the EBV value of TNB and NBA of EHL pigs. Meanwhile, we used the phenotypic data of KS-MS pig to calculate the EBV value of TNB and NBA of MS pigs. Microsoft Excel 2013 was used for gene frequency analysis in 10 pig populations. 


\subsubsection{EBV Calculation}

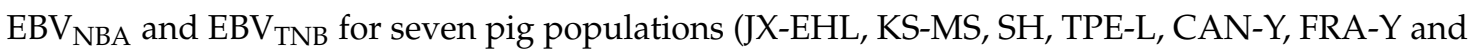
USA-Y pigs) with more than 150 individuals were determined based on the pooled data across all parties using the DMU software [15].

$$
\mathrm{Y}_{\mathrm{ijklmn}}=\mu+(\mathrm{H} / \mathrm{Y} / \mathrm{S})_{\mathrm{i}}+(\mathrm{HYS} / \mathrm{YS})_{\mathrm{j}}+\mathrm{PA}_{\mathrm{k}}+\mathrm{P}_{1}+\mathrm{A}_{\mathrm{m}}+\mathrm{B}_{\mathrm{n}}+\mathrm{e}_{\mathrm{ijklmn}}
$$

where $\mathrm{Y}_{\mathrm{ijklmn}}$ is the litter size phenotype; $\mu$ is the overall mean; $(\mathrm{H} / \mathrm{Y} / \mathrm{S})_{\mathrm{i}}$ is the fixed effect of herd or year or season, (HYS/YS) $)_{j}$ is the random effect of herd-year-season or year-season: when one population has multiple herds, $\mathrm{H}_{\mathrm{i}}$ as the fixed effect, $\mathrm{HYS}_{\mathrm{j}}$ as the random effect [16]; when one population only has one herd, $(\mathrm{Y} / \mathrm{S})_{\mathrm{i}}$ is the fixed effect of year or season according to the $p$ of the association between the year/season and NBA and TNB using ANOVA analysis of SPSS (Table S2), YS $\mathrm{s}_{\mathrm{j}}$ is the random effect of year-season; $\mathrm{PA}_{\mathrm{k}}$ is the fixed effect of parity; $\mathrm{P}_{1}$ is the random effect of permanent environment; $A_{m}$ represents random additive genetic effect; $B_{n}$ is the random effect of service boar and $e_{i j k l m n}$ is the random residual effect.

\subsubsection{Two Association Analysis Methods}

Association analyses of $r$ s339939442 with NBA and TNB of all parity in EHL, MS, SH, TPE-L, CAN-Y, USA-Y and FRA-Y pigs were conducted. Two analytical methods were used to identify whether rs339939442 in the AHR gene is a potential causal mutation affecting the litter size.

The first method of association analysis of $r s 339939442$ with litter size was performed by the mixed linear model with SAS 9.2 software (SAS Institute lnc, Cary, NC, USA):

$$
\mathrm{Y}_{\mathrm{ijklmno}}=\mu+(\mathrm{H} / \mathrm{Y} / \mathrm{S})_{\mathrm{i}}+(\mathrm{HYS} / \mathrm{YS})_{\mathrm{j}}+\mathrm{PA}_{\mathrm{k}}+\mathrm{P}_{1}+\mathrm{G}_{\mathrm{m}}+\mathrm{A}_{\mathrm{n}}+\mathrm{B}_{\mathrm{o}}+\mathrm{e}_{\mathrm{ijklmno}}
$$

where $\mathrm{Y}_{\mathrm{ijklmno}}$ is the litter size phenotype; $\mu$ is the overall mean; $(\mathrm{H} / \mathrm{Y} / \mathrm{S})_{\mathrm{i}}$ is the fixed effect of herd or year or season, $(\mathrm{HYS} / \mathrm{YS})_{j}$ is the random effect of herd-year-season or year-season: when one population has multiple herds, $\mathrm{H}_{\mathrm{i}}$ as the fixed effect, $\mathrm{HYS}_{\mathrm{j}}$ as the random effect [16], when one population has only one herd, $(\mathrm{Y} / \mathrm{S})_{\mathrm{i}}$ is the fixed effect of year or season according to the $p$ of the association between the year or season and NBA and TNB using ANOVA analysis of SPSS software (Table S1), $\mathrm{YS}_{\mathrm{j}}$ is the random effect of year-season; $\mathrm{PA}_{\mathrm{k}}$ is the fixed effect of parity; $\mathrm{Pl}$ is the random effect of permanent environment; $\mathrm{Gm}$ is the fixed effect of genotype; $A_{n}$ represents random additive genetic effect; $B_{o}$ is the random effect of service boar and $\mathrm{e}_{\mathrm{ijk} k \mathrm{mno}}$ is the random residual effect. Since the limited number of populations, we did not perform association analyses of $r s 339939442$ with the litter size of Southern Chinese pigs including WZS and BMX pigs.

The second method of association analysis of $r s 339939442$ with litter size was performed by using ANOVA analysis of SPSS software to calculate the association between $r s 339939442$ and EBVNBA/EBVTNB for each pig population [8]. The sample size for calculation of the EBVNBA/EBVTNB for each pig population was larger than that of association analysis since some sows had been eliminated before sampling in each pig population.

\section{Results}

\subsection{Phenotypic Variation of NBA and TNB within Seven Pig Populations}

The phenotype description of the NBA and TNB of the seven pig populations were shown in Tables 1 and 2. There was no difference in litter size between EHL and MS pigs, which both were Chinese Jianghai pigs. The litter size of EHL and MS pigs were significantly higher than that of SH (Chinese cultivated pigs) and TPE-L (Chinese lean meat pigs) pigs $(p<0.01)$. In Western lean meat pig populations, CAN-Y sows have the highest litter size, while USA-Y sows have the lowest reproductive performance $(p<0.01)$. We noticed that the variation coefficients of NBA and TNB exceed $20 \%$ in all pig populations. 
Table 1. Descriptive statistics of the number of born alive (NBA) in seven pig populations.

\begin{tabular}{ccccccc}
\hline Category & Breed & $\mathbf{N}_{\text {sow }}$ & $\mathbf{N}_{\text {parity }}$ & Range $^{\mathbf{1}}$ & Mean $\pm \mathbf{S E}$ & CV $\%$ \\
\hline \multirow{2}{*}{ Chinese indigenous pigs } & EHL & 571 & 2343 & $6-25$ & $13.30 \pm 0.06$ & 23.05 \\
Chinese cultivated breed & MS & 395 & 1684 & $6-23$ & $13.11 \pm 0.07$ & 20.32 \\
Chinese lean meat pigs & TPE-L & 3023 & 9903 & $6-21$ & $10.58 \pm 0.03$ & 23.75 \\
& CAN-Y & 1235 & 2992 & $6-26$ & $14.23 \pm 0.06$ & 23.06 \\
Western lean meat pigs & USA-Y & 365 & 1215 & $6-18$ & $10.31 \pm 0.07$ & 23.25 \\
& FRA-Y & 359 & 697 & $6-19$ & $11.94 \pm 0.10$ & 21.99 \\
\hline
\end{tabular}

$\mathrm{N}_{\text {sow }}$ represents the number of sows; $\mathrm{N}_{\text {parity }}$ represents the number for total parities; $\mathrm{CV}$ represents the coefficient of variation; EHL represents Erhualian pig; MS represents Meishan pig; SH representative Suhuai pig; TPE-L represents Chinese lean-type Taiwanese Landrace pig; CAN-Y represents Canadian Yorkshire pig; USA-Y represents American Yorkshire pig; FRA-Y presents French Yorkshire pig. ${ }^{1}$ Range of NBA from the smallest value to the largest value.

Table 2. Descriptive statistics of the total number of born (TNB) in seven pig populations.

\begin{tabular}{ccccccc}
\hline Category & Breed & $\mathbf{N}_{\text {sow }}$ & $\mathbf{N}_{\text {parity }}$ & Range $^{\mathbf{1}}$ & Mean $\pm \mathbf{S E}$ & CV \% \\
\hline \multirow{2}{*}{ Chinese indigenous pigs } & EHL & 574 & 2367 & $6-29$ & $13.90 \pm 0.07$ & 23.81 \\
Chinese Cultivated breed & MS & 396 & 1708 & $6-24$ & $13.83 \pm 0.07$ & 21.14 \\
Chinese lean meat pigs & TPE-L & 345 & 2465 & $6-20$ & $10.76 \pm 0.05$ & 20.62 \\
& CAN-Y & 1252 & 10,264 & $6-26$ & $11.20 \pm 0.03$ & 24.26 \\
Western lean meat pigs & USA-Y & 365 & 1236 & $6-28$ & $15.76 \pm 0.06$ & 22.50 \\
& FRA-Y & 359 & 704 & $6-20$ & $12.26 \pm 0.10$ & 20.60 \\
\hline
\end{tabular}

$\mathrm{N}_{\text {sow }}$ represents the number of sows; $\mathrm{N}_{\text {parity }}$ represents the number for total parities; $\mathrm{CV}$ represents the Coefficient of variation; EHL represents Erhualian pig; MS represents Meishan pig; SH representative Suhuai pig; TPE-L represents Chinese lean-type Taiwanese Landrace pig; CAN-Y represents Canadian Yorkshire pig; USA-Y represents American

Yorkshire pig; FRA-Y presents French Yorkshire pig. ${ }^{1}$ Range of TNB from the smallest value to the largest value.

\subsection{Genetic Polymorphism in Ten Pig Populations}

The rs339939442 was identified to be polymorphic in all 10 pig populations (EHL, MS, BMX, WZS, JXH, SH, TPE-L, CAN-Y, USA-Y and FRA-Y) and the data of gene polymorphism were shown in Table 3. The genotypes of this locus represented skewed distribution in most populations including EHL, MS, BMX, WZS, JXH, SH and USA-Y. There were no TT genotype individuals in JXH, BMX and WZS pig populations. Except for TPE-L pigs, the frequency of TT genotype was the least in all three genotypes within the other nine pig populations.

Table 3. Genetic polymorphism analysis in 10 pig populations.

\begin{tabular}{|c|c|c|c|c|c|c|c|}
\hline \multirow{2}{*}{ Category } & \multirow{2}{*}{ Breed } & \multirow{2}{*}{$\mathbf{N}$} & \multicolumn{3}{|c|}{ Genotype Frequency } & \multicolumn{2}{|c|}{ Allele Frequency } \\
\hline & & & GG (n) & GT (n) & TT (n) & G & $\mathbf{T}$ \\
\hline \multirow{3}{*}{ Chinese Jianghai pigs } & EHL & 363 & $0.791(287)$ & $0.198(72)$ & $0.011(4)$ & 0.890 & 0.110 \\
\hline & MS & 273 & $0.740(202)$ & $0.245(67)$ & $0.015(4)$ & 0.863 & 0.137 \\
\hline & $\mathrm{BMX}$ & 32 & $0.875(28)$ & $0.125(4)$ & $0(0)$ & 0.938 & 0.062 \\
\hline \multirow{2}{*}{ South China pigs } & WZS & 20 & $0.950(19)$ & $0.050(1)$ & $0(0)$ & 0.975 & 0.025 \\
\hline & $\mathrm{JXH}$ & 62 & $0.984(61)$ & $0.016(1)$ & $0(0)$ & 0.992 & 0.008 \\
\hline Chinese cultivated breed & $\mathrm{SH}$ & 314 & $0.634(199)$ & $0.334(105)$ & $0.032(10)$ & 0.801 & 0.199 \\
\hline \multirow[t]{2}{*}{ Chinese lean meat pigs } & TPE-L & 351 & $0.142(50)$ & $0.490(172)$ & $0.368(129)$ & 0.387 & 0.613 \\
\hline & CAN-Y & 425 & $0.301(128)$ & $0.525(223)$ & $0.174(74)$ & 0.564 & 0.436 \\
\hline \multirow[t]{2}{*}{ Western lean meat pigs } & USA-Y & 345 & $0.751(259)$ & $0.229(79)$ & $0.020(7)$ & 0.865 & 0.135 \\
\hline & FRA-Y & 359 & $0.418(150)$ & $0.485(174)$ & $0.097(35)$ & 0.660 & 0.340 \\
\hline
\end{tabular}

$\mathrm{N}$ represents the total genotyped number; $\mathrm{n}$ represents the number of different genotyped individuals; EHL represents Erhualian pig; MS represents Meishan pig; BMX represents Bamaxiang pig; WZS represents Wuzhishan pig; JXH represents JiaXinghei pig; SH representative Suhuai pig; TPE-L represents Chinese lean-type Taiwanese Landrace pig; CAN-Y represents Canadian Yorkshire; USA-Y represents American Yorkshire; FRA-Y presents French Yorkshire. 


\subsection{Association Analysis of rs339939442 in the AHR Gene with Litter Size}

\subsubsection{Association Analysis of rs339939442 in the AHR Gene with NBA/TNB}

The results of association of $r s 339939442$ in the AHR gene with the NBA/TNB in EHL (JX-EHL, CS-EHL and ST-EHL), MS (KS-MS, ST-MS and TC-MS), SH, TPE-L, CAN-Y, USA-Y and FRA-Y pigs were shown in Table 4. In SH pig population, rs339939442 was significantly associated with NBA/TNB $(p<0.05)$, and the TT genotype was the advantageous genotype. In FRA-Y population, there was a tendency $(p<0.1)$ of association between rs339939442 with litter size. Whereas, there were no association between rs339939442 in the AHR gene and the litter size of EHL, MS, TPE-L, CAN-Y and USA-Y pigs.

Table 4. Association of $A H R$ gene with the number of born alive (NBA) and the total number of born (TNB) in seven pig populations.

\begin{tabular}{ccccccc}
\hline \multirow{2}{*}{ Breed } & Genotype & N & \multicolumn{2}{c}{ NBA } & \multicolumn{2}{c}{ TNB } \\
\cline { 3 - 6 } & & & Mean \pm SE & $p$ & Mean \pm SE & $p$ \\
\hline \multirow{3}{*}{ EHL } & GG & 287 & $13.63 \pm 0.17$ & & $14.55 \pm 0.20$ & \\
& GT & 72 & $13.70 \pm 0.24$ & 0.359 & $14.69 \pm 0.27$ & 0.613 \\
& TT & 4 & $14.71 \pm 0.76$ & & $15.24 \pm 0.81$ & \\
MS & GG & 202 & $12.78 \pm 0.10$ & & $13.62 \pm 0.16$ & \\
& GT & 67 & $13.04 \pm 0.18$ & 0.419 & $13.96 \pm 0.23$ & 0.308 \\
& TT & 4 & $13.06 \pm 0.75$ & & $13.90 \pm 0.84$ & \\
SH & GG & 199 & $9.63 \pm 0.17 \mathrm{~b}$ & & $10.69 \pm 0.20^{\mathrm{b}}$ & \\
& GT & 105 & $9.97 \pm 0.20 \mathrm{a}, \mathrm{b}$ & 0.003 & $11.14 \pm 0.22 \mathrm{a}$ & 0.004 \\
& TT & 10 & $10.82 \pm 0.42 \mathrm{a}$ & & $11.66 \pm 0.45^{\mathrm{a}, \mathrm{b}}$ & \\
TPE-L & GG & 50 & $11.15 \pm 0.32$ & & $11.51 \pm 0.33$ & \\
& GT & 172 & $11.15 \pm 0.24$ & 0.968 & $11.72 \pm 0.25$ & 0.726 \\
& TT & 129 & $11.10 \pm 0.26$ & & $11.75 \pm 0.26$ & \\
CAN-Y & GG & 128 & $14.68 \pm 0.27$ & & $16.62 \pm 0.31$ & \\
& GT & 223 & $14.91 \pm 0.23$ & 0.558 & $16.86 \pm 0.26$ & 0.654 \\
& TT & 74 & $14.98 \pm 0.31$ & & $16.82 \pm 0.34$ & \\
USA-Y & GG & 259 & $10.23 \pm 0.10$ & & $10.69 \pm 0.14$ & \\
& GT & 79 & $10.37 \pm 0.16$ & 0.595 & $10.90 \pm 0.20$ & 0.501 \\
& TT & 7 & $9.90 \pm 0.53$ & & $10.36 \pm 0.60$ & \\
FRA-Y & GG & 150 & $11.66 \pm 0.29$ & & $12.03 \pm 0.24$ & \\
& GT & 174 & $12.13 \pm 0.29$ & 0.076 & $12.49 \pm 0.23$ & 0.073 \\
& TT & 35 & $12.14 \pm 0.42$ & & $12.49 \pm 0.37$ & \\
\hline
\end{tabular}

$\mathrm{N}$ represents the genotyped number; ${ }^{\mathrm{a}, \mathrm{b}}$ values within the column indicated by different superscripts are significantly $(p<0.05)$ different; EHL represents Erhualian pig; MS represents Meishan pig; SH representative Suhuai pig; TPE-L represents Chinese lean-type Taiwanese Landrace pig; CAN-Y represents Canadian Yorkshire; USA-Y represents American Yorkshire; FRA-Y presents French Yorkshire.

\subsubsection{Association Analysis between rs339939442 in the $A H R$ Gene and $\mathrm{EBV}_{\mathrm{NBA}} / \mathrm{EBV}_{\mathrm{TNB}}$}

The result of the association of $r s 339939442$ in the $A H R$ gene with the $\mathrm{EBV}_{\mathrm{TNB}}$ and $\mathrm{EBV}_{\mathrm{NBA}}$ in seven pig populations (JX-EHL, KS-MS, SH, TPE-L, CAN-Y, USA-Y and FRA-Y) is shown in Table 5. The rs339939442 was significantly associated with the $\operatorname{EBV}_{\mathrm{NBA}}$ and $\operatorname{EBV}_{\mathrm{TNB}}(p<0.01)$ in the $\mathrm{SH}$ population. In the FRA-Y population, the rs339939442 was also significantly associated with $\mathrm{EBV}_{\mathrm{NBA}}$ and $\mathrm{EBV}_{\mathrm{TNB}}(p<0.01)$. Whereas, there were no association between $r$ s339939442 in the AHR gene and litter size in the other five pig populations. 
Table 5. Association of $A H R$ gene with the $\mathrm{EBV}_{\mathrm{NBA}}$ and $\mathrm{EBV}_{\mathrm{TNB}}$ in seven pig populations.

\begin{tabular}{|c|c|c|c|c|c|c|}
\hline \multirow{2}{*}{ Breed } & \multirow{2}{*}{ Genotype } & \multirow{2}{*}{$\mathbf{N}$} & \multicolumn{2}{|l|}{ NBA } & \multicolumn{2}{|l|}{ TNB } \\
\hline & & & Mean $\pm S E$ & $p$ & Mean \pm SE & $p$ \\
\hline \multirow{3}{*}{ JX-EHL } & GG & 122 & $-0.337 \pm 0.060$ & \multirow{3}{*}{0.176} & $-0.327 \pm 0.057$ & \multirow{3}{*}{0.222} \\
\hline & GT & 47 & $-0.124 \pm 0.092$ & & $-0.134 \pm 0.091$ & \\
\hline & $\mathrm{TT}$ & 3 & $-0.084 \pm 1.068$ & & $-0.221 \pm 0.912$ & \\
\hline \multirow{3}{*}{ KS-MS } & GG & 99 & $0.021 \pm 0.028$ & \multirow{3}{*}{0.398} & $0.019 \pm 0.037$ & \multirow{3}{*}{0.189} \\
\hline & GT & 51 & $0.069 \pm 0.047$ & & $0.132 \pm 0.065$ & \\
\hline & $\mathrm{TT}$ & 3 & $0.205 \pm 0.169$ & & $0.246 \pm 0.190$ & \\
\hline \multirow{3}{*}{$\mathrm{SH}$} & GG & 199 & $-0.014 \pm 0.031^{\mathrm{B}, \mathrm{b}}$ & \multirow{3}{*}{0.001} & $-0.012 \pm 0.017^{b}$ & \multirow{3}{*}{0.004} \\
\hline & GT & 105 & $0.097 \pm 0.047^{\mathrm{A}, \mathrm{B}, \mathrm{a}}$ & & $0.062 \pm 0.029^{a, b}$ & \\
\hline & $\mathrm{TT}$ & 10 & $0.492 \pm 0.218^{\mathrm{A}, \mathrm{a}}$ & & $0.212 \pm 0.108^{a}$ & \\
\hline \multirow{3}{*}{ TPE-L } & GG & 50 & $0.318 \pm 0.077$ & \multirow{3}{*}{0.533} & $0.169 \pm 0.085$ & \multirow{3}{*}{0.860} \\
\hline & GT & 172 & $0.320 \pm 0.044$ & & $0.213 \pm 0.046$ & \\
\hline & $\mathrm{TT}$ & 129 & $0.247 \pm 0.05$ & & $0.181 \pm 0.057$ & \\
\hline \multirow{4}{*}{ CAN-Y } & GG & 128 & $0.348 \pm 0.046$ & \multirow{3}{*}{0.311} & $0.405 \pm 0.045$ & \multirow{3}{*}{0.188} \\
\hline & GT & 223 & $0.388 \pm 0.040$ & & $0.431 \pm 0.040$ & \\
\hline & $\mathrm{TT}$ & 74 & $0.476 \pm 0.072$ & & $0.555 \pm 0.077$ & \\
\hline & GG & 259 & $-0.072 \pm 0.020$ & \multirow{3}{*}{0.650} & $-0.052 \pm 0.021$ & \multirow{3}{*}{0.527} \\
\hline \multirow{2}{*}{ USA-Y } & GT & 79 & $-0.035 \pm 0.034$ & & $-0.005 \pm 0.036$ & \\
\hline & $\mathrm{TT}$ & 7 & $-0.027 \pm 0.179$ & & $-0.008 \pm 0.184$ & \\
\hline \multirow{3}{*}{ FRA-Y } & GG & 150 & $-0.008 \pm 0.004^{\mathrm{B}, \mathrm{b}}$ & \multirow{3}{*}{0.003} & $-0.021 \pm 0.013^{\mathrm{B}, \mathrm{b}}$ & \multirow{3}{*}{0.006} \\
\hline & GT & 174 & $0.008 \pm 0.003^{\mathrm{A}, \mathrm{a}}$ & & $0.030 \pm 0.011^{\mathrm{A}, \mathrm{a}}$ & \\
\hline & $\mathrm{TT}$ & 35 & $0.007 \pm 0.007^{\mathrm{A}, \mathrm{B}, \mathrm{a}, \mathrm{b}}$ & & $0.032 \pm 0.022 \mathrm{~A}, \mathrm{~B}, \mathrm{a}, \mathrm{b}$ & \\
\hline
\end{tabular}

$\mathrm{N}$ represents the genotyped number; ${ }^{\mathrm{A}, \mathrm{B}}$ values within the column indicated by different superscripts are significantly $(p<0.01)$ different; ${ }^{a}, b$ values within the column indicated by different 1superscripts are significantly $(p<0.05)$ different; JX-EHL represents Jiaoxi Erhualian pig; KS-MS represents Kunshan Meishan pig; SH representative Suhuai pig; TPE-L represents Chinese lean-type Taiwanese Landrace pig; CAN-Y represents Canadian Yorkshire; USA-Y represents American Yorkshire; FRA-Y presents French Yorkshire.

\section{Discussion}

The litter size trait is the main focus of the swine industry and is affected by many environmental and genetic factors [17-19]. Detection of the exact genetic markers or genes associated with litter size in pigs may have a significant impact on improving reproductive traits and thus improve the accuracy of selection [20].

AHR gene is expressed in the liver, kidney, lung, thymus, brain and reproductive organs of many mammals [21-23]. It is a gene found in recent years that may affect the growth of follicles by regulating estradiol secretion [24]. It also was found to play an important role in regulating the number of sinusoidal follicles and the formation of primary follicles [25]. The activated expression of the $A H R$ gene is susceptible to tetrachlorodibenzo-p-dioxin (TCDD). In boars, the combination of $A H R$ and TCDD can cause endocrine disorders, reduced sperm, altered sexual behavior and reduced fertility [26]. In sows, the combination of TCDD and AHR affects the follicular phase and luteinizing steroid hormones in the sow's estrus cycle [27]. Activated AHR can cause ovarian dysfunction in females and decrease and degeneration of sperm cells in males. Histomorphological analysis was performed using ovarian tissue from $4 \mathrm{~d}$-born mice, and it was found that the number of starting follicles in the ovaries of $A H R$ gene-deficient mice was approximately twice that of wild-type mice [28]. It was also found that the $A H R$ gene was considered to be a Chinese high-yield genomic fragment introduced into the Western pig genome to improve the litter size and rs339939442 in the AHR gene was considered to be a potential causal mutation for litter size in European commercial lines [8]. In order to identify whether $r s 339939442$ is polymorphic and has an influence on the litter size in Chinese and Western pigs, 10 diverse pig populations including five Chinese indigenous breeds, one Chinese cultivated breed, one Chinese lean-type breed, two North American lean meat pig breeds and one European lean meat pig breed were chosen to carry out the test. 
NBA and TNB were chosen as the phenotypes of this research, and many factors that affect them such as herd, year, season and boar had been considered in association analysis. EBV for TNB and NBA of pig were thus explored to avoid systematic environmental impacts on our conclusion drawn in this study [8]. The sample size for descriptive analysis of phenotype and the calculation of the $\mathrm{EBV}_{\mathrm{NBA}} / \mathrm{EBV}_{\mathrm{TNB}}$ was larger than that of association analysis since some sows had been eliminated before sampling. Moreover, the sample size for Chinese indigenous pigs including EHL and MS pig is somewhat difficult to increase any more [14].

EHL pig is the representative of the high fecundity of Chinese local pigs [29], and MS pig is one of the Chinese breeds that were introduced into France in 1979 due to high fertility [30]. We found that the litter size of EHL and MS pigs were significantly higher than that of SH and TPE-L pigs. SH pig population is a unique cultivar possessing ancestries of Chinese Huai pig and British Yorkshire pig [13]. There are only a few related studies on reproductive traits for SH pig breed [31-33]. Descriptive statistics of NBA and TNB indicated that the litter size was low in SH pigs, and it is urgent to improve their litter size through molecular breeding. The strictly organized breeding program was adopted to improve and develop livestock breeds, Britain, in particular, was the main center of the early improvement of pig breeds and cultivated the famous Yorkshire pigs [34]. FRA-Y was regarded as the pigs most likely to contain ancestries of Chinese local pigs [35]. Canada and the United States are far from the origin country of the Yorkshire-Britain and FRA-Y, CAN-Y and USA-Y were thus used in the study. Coefficient of variation (CV) of TNB and NBA reached more than $20 \%$ in the seven studied populations including EHL, MS, SH, TPE-L, CAN-Y, USA-Y and FRA-Y pigs, indicated a large phenotypic variation in litter size within each population.

By sequencing the PCR amplification products, $r$ s339939442 locus was found located in the 10th exon region of the $A H R$ gene, and the $r s 339939442$ was identified to be polymorphic in all 10 pig populations. Moreover, the genotype frequency of $r s 339939442$ represented skewed distribution in most populations including EHL, MS, BMX, WZS, JXH, SH and USA-Y. The frequency of the TT genotype was small and was not more than 0.2 in Chinese indigenous pig groups, and even no TT genotype individuals were found in the BMA, WZS and JXH pig populations. The small size of the population might be the main cause for the absence of the TT genotype in these three pig populations, in which the number was only 32, 20 and 62 respectively. Interestingly, the frequency of the TT genotype was small and was not more than 0.2 in all 10 pig groups but Taiwanese Landrace pigs (TPE-L). This result is maybe due to: (1) the different genetic background between TPE-L pigs and the other populations; (2) since the $A H R$ gene is involved in multiple traits [8,36], it could be that different direct or indirect selection acted on the alleles of $r s 339939442$ under different breeding goals between TPE-L pigs and the other populations.

We found that $r s 339939442$ in the AHR gene was associated with the NBA and TNB of SH pig population through two methods. This may be attributable to that $\mathrm{SH}$ pigs contained $75 \%$ British Yorkshire pigs ancestry. We also found $r$ s339939442 was associated with the NBA and TNB of FRA-Y. The result was consistent with that $r s 339939442$ locus was associated with the litter size of European pigs [8]. Previous research has also shown that the AHR gene influence estrous cycle and ovarian development and fertility [12,25,37]. Therefore, our results and previous results can suggest that the $A H R$ gene has a certain role in the reproduction process. We found that TT genotype was the advantageous genotype for NBA and TNB. This result indicated that it is an effective way to select TT genotyped individuals to increase the litter size in SH and FRA-Y pigs. Our results verified that rs339939442 in the AHR gene was a potential marker to improve litter size in European commercial lines and the pigs containing ancestries of European commercial lines.

However, there were no association between rs339939442 in the AHR gene and the litter size of EHL, MS, TPE-L, CAN-Y and USA-Y pigs. Association of $r s 339939442$ in the AHR gene with litter size is inconsistent among different pig populations like other candidate gene markers for litter size [38]. This result is most likely due to: (1) the different genetic background between European commercial lines and these populations and (2) rs339939442 is only in linkage disequilibrium with the causal 
mutation of litter size. Since recombination exists between the SNP and the causal mutation in the EHL, MS, TPE-L, CAN-Y and USA-Y pigs, no significant association can be detected.

\section{Conclusions}

Taken together, rs339939442 in the AHR gene had polymorphism in both Chinese indigenous pigs and Western commercial pigs, whereas rs339939442 was significantly associated with litter size only in FRA-Y and Chinese cultivated SH pigs containing British Yorkshire pigs ancestry. Our results indicated that rs339939442 was a potential marker to improve litter size in European commercial lines and the pigs containing ancestries of European commercial lines and rs339939442 maybe only in linkage disequilibrium with the causative mutation for litter size.

Supplementary Materials: The following are available online at http://www.mdpi.com/2076-2615/10/1/11/s1, Table S1: The specific composition for different analysis of the animals in this study, Table S2: Correlation analysis between year/season and litter size.

Author Contributions: Conceptualization, R.H. and P.L.; Formal analysis, Q.Z. and X.M.; Investigation, Q.Z., N.J., W.Z., C.G., M.Z., P.N., Z.Z., Q.L. and J.Z.; Methodology, P.L. and R.H.; Project administration, P.L. and R.H.; Writing-original draft, Q.Z. and P.L.; Writing—review and editing, P.L. and R.H. All authors have read and agreed to the published version of the manuscript.

Funding: This work is financially supported by the National Natural Science Foundation of China (NO 31601923); the Ministry of Agriculture and Rural Affairs Joint Projects for the National High Quality and Lean Pig Breeding (19190540), the Key Project of Jiangsu Agricultural New Variety Innovation (PZCZ201732), the project of Jiangsu Agricultural (pig) Industry Technology System (JATS(2019)418, JATS(2019)189) and the Construction of Huaian Academy of Nanjing Agricultural University (BM2017020).

Conflicts of Interest: The authors declare that they have no conflict of interest.

\section{References}

1. Schneider, J.F.; Rempel, L.A.; Rohrer, G.A. Genome-wide association study of swine farrowing traits. Part I: Genetic and genomic parameter estimates. J. Anim. Sci. 2012, 90, 3353-3359. [CrossRef] [PubMed]

2. Zhang, S.; Yang, J.; Wang, L.; Li, Z.; Pang, P.; Li, F. SLA-11 mutations are associated with litter size traits in Large White and Chinese DIV pigs. Anim. Biotechnol. 2019, 30, 212-218. [CrossRef] [PubMed]

3. Ran, X.Q.; Pan, H.; Huang, S.H.; Liu, C.; Niu, X.; Li, S.; Wang, J.F. Copy number variations of MTHFSD gene across pig breeds and its association with litter size traits in Chinese indigenous Xiang pig. J. Anim. Physiol. Anim. Nutr. 2018. [CrossRef] [PubMed]

4. National Livestock and Genetic Resources Commission. Chinese Pig Breed Records; Shanghai Science and Technology Press: Shanghai, China, 1986.

5. China National Commission of Animal Genetic Resources. Animal Genetic Resources in China Pigs; China Agriculture Press: Beijing, China, 2011.

6. Bidanel, J.P.; Bonneau, M.; Pointillart, A.; Gruand, J.; Mourot, J.; Demade, I. Effects of exogenous porcine somatotropin (pST) administration on growth performance, carcass traits, and pork meat quality of Meishan, Pietrain, and crossbred gilts. J. Anim. Sci. 1991, 69, 3511-3522. [CrossRef] [PubMed]

7. Kim, K.S.; Choi, C.B. Genetic structure of Korean native pig using microsatellite markers. Korean J. Genet. 2002, 24, 1-7.

8. Bosse, M.; Megens, H.J.; Frantz, L.A.; Madsen, O.; Larson, G.; Paudel, Y.; Duijvesteijn, N.; Harlizius, B.; Hagemeijer, Y.; Crooijmans, R.P. Genomic analysis reveals selection for Asian genes in European pigs following human-mediated introgression. Nat. Commun. 2014, 5, 4392. [CrossRef]

9. Walisser, J.A.; Bunger, M.K.; Glover, E.; Bradfield, C.A. Gestational exposure of Ahr and Arnt hypomorphs to dioxin rescues vascular development. Proc. Natl. Acad. Sci. USA 2004, 101, 16677-16682. [CrossRef]

10. Feng, S.; Cao, Z.; Wang, X. Role of aryl hydrocarbon receptor in cancer. Biochim. Biophys. Acta 2013, 1836, 197-210. [CrossRef]

11. Baba, T.; Mimura, J.; Nakamura, N.; Harada, N.; Yamamoto, M.; Morohashi, K.; Fujii-Kuriyama, Y. Intrinsic function of the aryl hydrocarbon (dioxin) receptor as a key factor in female reproduction. Mol. Cell. Biol. 2005, 25, 10040-10051. [CrossRef] 
12. Jablonska, O.; Piasecka, J.; Ostrowska, M.; Sobocinska, N.; Wasowska, B.; Wasowka, B.; Ciereszko, R.E. The expression of the aryl hydrocarbon receptor in reproductive and neuroendocrine tissues during the estrous cycle in the pig. Anim. Reprod. Sci. 2011, 126, 221-228. [CrossRef]

13. Wang, B.L.; Li, P.; Zhou, W.D.; Gao, C.; Liu, H.; Li, H.X.; Niu, P.P.; Zhang, Z.P.; Li, Q.; Zhou, J.; et al. Association of twelve candidate gene polymorphisms with the intramuscular fat content and average backfat thickness of Chinese Suhuai pigs. Animals 2019, 9, 858. [CrossRef] [PubMed]

14. Ma, X.; Li, P.H.; Zhu, M.X.; He, L.C.; Sui, S.P.; Gao, S.; Su, G.S.; Ding, N.S.; Huang, Y.; Lu, Z.Q. Genome-wide association analysis reveals genomic regions on Chromosome 13 affecting litter size and candidate genes for uterine horn length in Erhualian pigs. Animal 2018, 12, 2453-2461. [CrossRef] [PubMed]

15. Madsen, P.; Sørensen, P.; Su, G.; Damgaard, L.H.; Thomsen, H.; Labouriau, R. DMU—A Package for Analyzing Multivariate Mixed Models in quantitative Genetics and Genomics. In Proceedings of the 8th World Congress on Genetics Applied to Livestock Production, Minas Gerais, Brazil, 13-18 August 2006.

16. Chauhan, V.P.S. Dairy sire evaluation fitting some of the herd-year-season effects as random. Livest. Prod. Sci. 1987, 16, 117-130. [CrossRef]

17. Sanchez-Davila, F.; Bernal-Barragan, H.; Padilla-Rivas, G.; Del Bosque-Gonzalez, A.S.; Vazquez-Armijo, J.F.; Ledezma-Torres, R.A. Environmental factors and ram influence litter size, birth, and weaning weight in Saint Croix hair sheep under semi-arid conditions in Mexico. Trop. Anim. Health Prod. 2015, 47, 825-831. [CrossRef] [PubMed]

18. Nielsen, B.; Su, G.; Lund, M.S.; Madsen, P. Selection for increased number of piglets at $\mathrm{d} 5$ after farrowing has increased litter size and reduced piglet mortality. J. Anim. Sci. 2013, 91, 2575-2582. [CrossRef]

19. Ajayi, B.; Akinokun, J. Evaluation of some litter traits and heritability estimates of Nigerian Indigenous pigs. Int. J. Appl. Agric. Apic. Res. 2013, 9, 113-119.

20. Rothschild, M.F.; Messer, L.; Day, A.; Wales, R.; Short, T.; Southwood, O.; Plastow, G. Investigation of the 1retinol-binding protein 4 (RBP4) gene as a candidate gene for increased litter size in pigs. Mamm. Genome 2000, 11, 75-77. [CrossRef]

21. Chirulli, V.; Marvasi, L.; Zaghini, A.; Fiorio, R.; Longo, V.; Gervasi, P.G. Inducibility of AhR-regulated CYP genes by beta-naphthoflavone in the liver, lung, kidney and heart of the pig. Toxicology 2007, 240, 25-37. [CrossRef]

22. Khorram, O.; Garthwaite, M.; Golos, T. Uterine and ovarian aryl hydrocarbon receptor (AHR) and aryl hydrocarbon receptor nuclear translocator (ARNT) mRNA expression in benign and malignant gynaecological conditions. Mol. Hum. Reprod. 2002, 8, 75-80. [CrossRef]

23. Hasan, A.; Fischer, B. Epithelial cells in the oviduct and vagina and steroid-synthesizing cells in the rabbit ovary express AhR and ARNT. Anat. Embryol. 2003, 207, 9-18. [CrossRef]

24. Barnett, K.R.; Tomic, D.; Gupta, R.K.; Miller, K.P.; Meachum, S.; Paulose, T.; Flaws, J.A. The aryl hydrocarbon receptor affects mouse ovarian follicle growth via mechanisms involving estradiol regulation and responsiveness. Biol. Reprod. 2007, 76, 1062-1070. [CrossRef] [PubMed]

25. Benedict, J.C.; Lin, T.M.; Loeffler, I.K.; Peterson, R.E.; Flaws, J.A. Physiological role of the aryl hydrocarbon receptor in mouse ovary development. Toxicol. Sci. 2000, 56, 382-388. [CrossRef] [PubMed]

26. Mandal, P.K. Dioxin: A review of its environmental effects and its aryl hydrocarbon receptor biology. J. Comp. Physiol. B 2005, 175, 221-230. [CrossRef] [PubMed]

27. Gregoraszczuk, E.L.; Zabielny, E.; Ochwat, D. Aryl hydrocarbon receptor (AhR)-linked inhibition of luteal cell progesterone secretion in 2,3,7,8-tetrachlorodibenzo-p-dioxin treated cells. J. Physiol. Pharmacol. 2001, 52, 303-311.

28. Robles, R.; Morita, Y.; Mann, K.K.; Perez, G.I.; Yang, S.; Matikainen, T.; Sherr, D.H.; Tilly, J.L. The aryl hydrocarbon receptor, a basic helix-loop-helix transcription factor of the PAS gene family, is required for normal ovarian germ cell dynamics in the mouse. Endocrinology 2000, 141, 450-453. [CrossRef]

29. He, L.C.; Li, P.H.; Ma, X.; Sui, S.P.; Gao, S.; Kim, S.W.; Gu, Y.Q.; Huang, Y.; Ding, N.S.; Huang, R.H. Identification of new single nucleotide polymorphisms affecting total number born and candidate genes related to ovulation rate in Chinese Erhualian pigs. Anim. Genet. 2016, 48, 48-54. [CrossRef]

30. Desautes, C.; Sarrieau, A.; Caritez, J.C.; Mormede, P. Behavior and pituitary-adrenal function in large white and Meishan pigs. Domest. Anim. Endocrinol. 1999, 16, 193-205. [CrossRef]

31. Qu, L.; Li, K.Z.; Wang, X.X. Effects of polymorphisms of FSHb gene on reproductive performances in Suhuai pigs. Anim. Husb. Vet. Med. 2008, 2, 24-28. 
32. Jie, C. Polymorphisms of seven functional genes and their correlation to production performance in Suhuai pigs. J. Nanjing Agric. Univ. 2008, 31, 102-106.

33. Fang, Y.Y.; Ma, X.; Yu, Y.; Li, Q.; Wang, W.Q.; Wang, L.W.; Ren, E.D.; Li, P.L.; Huang, R.H. Polymorphism analysis of genes ESR1 and FSH $\beta$ in Suhuai pigs and correlation analysis with reproductive traits. Anim. Husb. Vet. Med. 2017, 49, 1-5.

34. Walton, J.R. Pigs: A handbook to the breeds of the world valerie porter mountfield, East Sussex Helm Information Ltd. Br. Vet. J. 1994, 150, 422. [CrossRef]

35. Zhao, P.; Yu, Y.; Feng, W.; Du, H.; Yu, J.; Kang, H.; Zheng, X.; Wang, Z.; Liu, G.E.; Ernst, C.W.; et al. Evidence of evolutionary history and selective sweeps in the genome of Meishan pig reveals its genetic and phenotypic characterization. GigaScience 2018, 7. [CrossRef] [PubMed]

36. Shimba, S.; Watabe, Y. Crosstalk between the AHR signaling pathway and circadian rhythm. Biochem. Pharmacol. 2009, 77, 560-565. [CrossRef] [PubMed]

37. Aftabi, Y.; Hosseinzadeh Colagar, A.; Mehrnejad, F.; Seyedrezazadeh, E.; Moudi, E. Aryl hydrocarbon receptor gene transitions (c.-742C > T; c.1661G >A) and idiopathic male infertility: A case-control study with in silico and meta-analysis. Environ. Sci. Pollut. Res. Int. 2017, 24, 20599-20615. [CrossRef] [PubMed]

38. Drogemuller, C.; Hamann, H.; Distl, O. Candidate gene markers for litter size in different German pig lines. J. Anim. Sci. 2001, 79, 2565-2570. [CrossRef] [PubMed]

(C) 2019 by the authors. Licensee MDPI, Basel, Switzerland. This article is an open access article distributed under the terms and conditions of the Creative Commons Attribution (CC BY) license (http://creativecommons.org/licenses/by/4.0/). 